\title{
Martin Buber e a fenomenologia: o encontro no DISCURSO FILOSÓFICO E PSICOLÓGICO
}

\author{
José Mauricio de Carvalho ${ }^{1}$ \\ Mauro Sérgio de Carvalho Tomaz ${ }^{2}$
}

Resumo: $\mathrm{O}$ fundamental da contribuiçẫo de Buber à fenomenologia existencial é atribuir às palavrasprincípio Eu-Tu e Eu-Isso, pela intencionalidade da consciência, papel decisivo no diálogo e no encontro. Isso ocorre pela presentificação e distanciamento dos debatedores. Essas palavras foram fundamentais para explicar as relações intersubjetivas e com o mundo, essenciais para esclarecer o discurso filosófico e científico. O que se apresentará nesta comunicação é o aprofundamento da distinção contida nas palavras-princípio e sua repercussão na relação terapeuta - paciente/cliente, nas clínicas psicológica e médica. Adicionalmente, comentar-se-á o diálogo que Buber estabeleceu com Freud e Jung, com o primeiro inserindo o sentido da historicidade na construção da vida para recusar a noçấo de cultura como projeção do Édipo e, com o segundo, recusando reduzir o diálogo com o sagrado a função psíquica.

Palavras-chave: Fenomenologia. Intencionalidade. Filosofia. Saúde. Psicologia.

O Isso é a crisálida, o Tu a borboleta. Porém, não como se fossem estados que se alternam nitidamente, mas, amiúde, são processos que se entrelaçam confusamente numa profunda dualidade (BUBER, 2006, p. 63).

\section{INTRODUÇÃo}

A apresentação de parte da obra de Martin Buber em um encontro de fenomenologia é apropriada, ${ }^{3}$ pois o filósofo se aproximou da fenomenologia

${ }_{1}$ Professor titular aposentado da UFSJ, professor do Centro Universitário Presidente Tancredo de Almeida Neves (UNIPTAN). if orcid.org/0000-0002-3534-5338. E-mail: josemauriciodecarvalho@ gmail.com. São Joáo del-Rei, MG, Brasil.

2 Escola Estadual Professora Maria Rita Lisboa Pereira Santoro. if orcid.org/0000-0001-5629-9310. E-mail: msctomaz@hotmail.com. Lambari, MG. Brasil.

${ }^{3}$ Von Zuben identifica o confronto do discurso filosófico e científico como um tema importante da fenomenologia, no capítulo 5 de Martin Buber, cumplicidade e diálogo (2003, p. 141): "O estudo da

http://dx.doi.org/10.1590/0101-3173.2020.v43n4.12.p203 
existencial, ao longo da vida, tornando-se importante representante do movimento ${ }^{4}$. Não se desconhece que há comentadores que defendam que a estruturação de Eu e Tu e o pensamento filosófico de Buber em geral dependa do seu conhecimento do hassídismo e que elementos hassídicos estejam na raiz de sua obra filosófica ${ }^{5}$. No entanto, mesmo que se admita essa hipótese, os livros Eu e Tu e do Diálogo e do Dialógico são textos de filosofia que refletem a formação filosófica do autor e seu conhecimento do debate neokantiano e fenomenológico na Alemanha, no início do século passado. Neste artigo (e no contexto deste encontro sobre fenomenologia), destacar-se-á o modo como aparecem, em sua obra, os discursos filosóficos e científicos ${ }^{6}$. E se sua formação judaica influenciou a escrita dos seus textos filosóficos, em contrapartida, não há dúvida de que sua formação filosófica influenciou seus escritos sobre os mitos hassídicos. Não é isso, contudo, o foco deste estudo.

A fenomenologia descreve o indivíduo como um ser que convive ou se relaciona, e isso aparece tanto no discurso filosófico como no científico. Esse tema revela seu significado, quando nos damos conta de que o homem vive sua existência como construção de sentido e está situado no tempo e no espaço. É nessa condição que se manifesta seu caráter intersubjetivo, no qual Buber situa a humanidade do homem, quer enquanto desenvolvimento pessoal, quer como membro da sociedade. Essa é uma forma de pensar que caracteriza a fenomenologia existencial, como ensina Luijpen (1973, p. 264):

obra de Buber por ocasiáo de uma Semana de Estudos consagrada à fenomenologia [...] não deixa de sugerir observaçôes concernentes à questão das duas ordens de discurso que são o discurso científico e o discurso filosófico".

${ }^{4}$ Fritz Heinemann aponta Martin Buber, no livro A filosofia no século XX, como representante destacado da escola fenomenológica existencial. Ele afirma (2006, p. 543) que "os representantes mais categorizados da tendência existencialista são na atualidade Karl Jaspers, Gabriel Marcel, Jean Paul Sartre e, num sentido mais lato, Martin Buber, Albert Camus e Nicolau Berdiaeff".

${ }^{5}$ Em A crisálida da Filosofia, Cromberg (2002, p. 31) afirma: "Aqueles que conheceram um pouco do hassidismo, seja a partir do material apresentado pelo próprio Buber, seja por outras fontes, percebem como uma das principais bases de Eu e Tu é o hassidismo." O livro de Mônica Cromberg é uma tentativa de familiarizar o leitor com o pensamento hassídico, para que ele perceba sua presença nos textos filosóficos.

${ }^{6}$ Heins Heimsoeth comenta, em A filosofia do século XX, esse aspecto da fenomenologia como se segue (1938, p. 34): "Partindo, no começo, do exame de questôes puramente relativas à teoria da ciências e fundando-se apenas em investigaçóes atinentes à crítica do conhecimento - procurando para esta uma mais vasta fundamentação (nas Investigações Lógicas, de Husserl, 1900) - esta nova metodologia e esta nova atitude mental não tardaram, com efeito, em chamar pouco a pouco a si, incluindo-os no seu campo de visão, uma enorme quantidade de novos domínios da consciência e da experiência, bem como campos da realidade objetiva, que em parte foram assim, pela primeira vez, abertos à reflexão e compreensão filosóficas". 
À primeira vista parece ser muito fácil demonstrar que a autenticidade da existência pressupóe outras existências, visto que nos referimos continuamente ao envolvimento do sujeito no mundo cultural. Ora, o mundo cultural é, por definição, um sistema de significados já estabelecidos por outros significados que funcionam quais correlatos de minha existência como cogito, como volo e como ago. Logo, seria absurdo não citar outras existências para explicar a minha existência.

As ciências do espírito haviam dedicado especial importância ao fato de que o outro podia ocupar na consciência o lugar do objeto. Essa questão foi contemplada por Heimsoeth, como se segue (1938, p. 44): "[...] o problema da experiência do outro, isto é, do Eu alheio, ou ainda do nosso saber alguma coisa de concreto sobre as outras pessoas fora de nossa consciência assume também um particular interesse atualmente”. No entanto, Martin Buber dirá mais que o que fora contemplado pelos fenomenólogos até então, ia pouco além do afirmado no neokantismo e no idealismo de Fichte sobre o diálogo e a intersubjetividade. Para Buber, não basta dizer que o homem se faz nas relaçôes sociais, é necessário explicitar que ele se estabelece no espaço do diálogo ${ }^{7}$, nas palavras-princípio e, especialmente, no que há entre elas, como se indicará a seguir.

\section{As PALAVRas PRINCÍPIOS}

Eu e Tu foi inicialmente pensado, em 1918, como parte de uma obra que contemplava outros assuntos, como as formas de vida religiosa, o conhecimento de Deus e de sua lei, a pessoa e a comunidade e o Poder e o Reino. O sucesso e o impacto dessa parte inicial, assim como o amadurecimento intelectual ocorrido entre o planejamento e a execução da obra, em 1922, levaram Buber a desistir de continuá-lo. O livro foi concebido na perspectiva fenomenológica, o que permitiu descrever o significado existencial das palavras-princípio, admitindo duas intencionalidades dinâmicas da consciência. $\mathrm{O}$ estilo hermético do livro exige mais que uma leitura rápida, pede um estudo de aprofundamento para revelar sua riqueza.

\footnotetext{
${ }^{7}$ Em Martin Buber, cumplicidade e diálogo, Newton von Zuben comenta esse aspecto no pensamento de Buber, como se segue (2003, p. 146): "é o diálogo a categoria existencial por excelência sobre a qual Buber busca fundar suas reflexóes. A sua proposta de se compreender a realidade humana através do prisma do dialógico é um exemplo de vínculo entre a experiência vivida e a reflexão, entre o pensamento e a ação".
} 
No livro Eu e Tu, Martin Buber se refere à dupla intencionalidade da consciência, através das "palavras-princípio". Há dois pares delas: Eu - Tu e Eu - Isso. Na segunda palavra, ele explica, é possível substituir o "Isso" por "Ele" ou "Ela" sem que haja alteração substancial no sentido. Esses pares de palavras apresentam as formas de relação que o homem tem com outro homem (ou espírito) e com as coisas. Elas expressam, como esclarece Antônio Sidekum (1979, p. 39), "[...] uma fenomenologia da relação, cujo princípio ontológico é a manifestação do ser ao homem, que o intui imediatamente pela contemplação". As palavras-princípio mostram a duplicidade de sentido do Eu nas relaçóes com o Tu e no encontro com o Isso. Igualmente contemplam a dualidade do mundo a que esse Eu se dirige, pois se revela como Tu e como Isso. Para Buber, a palavra-princípio fundamenta a existência humana que brota da relação.

No entanto, apenas a palavra-princípio $\mathrm{Eu}$ - Tu pode ser proferida pelo ser, em sua totalidade ${ }^{8}$. Ao afirmar tal coisa, o que Buber pretende dizer é que tanto o Tu quanto o Isso das palavras-princípio estáo conectados a um Eu, mas que o Tu guarda um modo diferente de ser com respeito ao Isso9. Dito de outro modo, significa "que não há um eu em si [...], pois para Buber [...] O Eu somente terá sentido se proferir uma das palavras princípio” (SIDEKUM, 1979 , p. 40). Isso quer dizer que o Eu a que Buber se refere não é um Euem-si, pois só pode existir na relação com o Tu ou em experiência com o Isso, portanto, numa dessas duas possibilidades de existir. Sobre as relaçóes que anunciam as palavras-princípio, comenta ainda Sidekum, no segundo capítulo de seu livro A intersubjetividade em Martin Buber (1979, p. 39):

A base da obra Eu e Tu não é constituída por conceitos abstratos, mas é a própria experiência existencial se revelando. Nós estabelecemos relações. É a palavra que nos introduz nas relaçôes. Fazemos da palavra um diálogo. Este diálogo é acima de tudo um diálogo existencial.

\footnotetext{
${ }^{8} \mathrm{Na}$ interpretação de von Zuben, essa palavra-princípio não foi pensada de forma abstrata, mas se refere à realidade existencial do homem (2003, p. 87): "ela é a própria experiência existencial se revelando. Buber efetua uma verdadeira fenomenologia da relação, cujo princípio ontológico é a manifestação do ser ao homem que o intui imediatamente pela contemplação".

${ }^{9}$ Trata-se de duas atitudes diferentes possíveis a todos os homens, conforme observa von Zuben (2003, p. 97): "O homem pelo simples fato de ser humano pode tomar qualquer uma das duas atitudes. Eu-Tu não é reservado às pessoas mais nobres e sábias, de melhor poder de acesso à cultura”. Porém, certamente, pode-se asseverar que depende de uma atitude moral, no sentido de considerar o outro um mundo singular que deve ser respeitado como tal e que náo pode ser objetivado. Isso se aufere das características da relação Eu-Tu: reciprocidade, presença, entrega, transcendência do tempo e espaço.
} 
As palavras-princípio diferenciam experiência e relação: experiência diz respeito ao contato do Eu com as coisas e com o mundo (Isso), que representa um distanciamento; a relação é vínculo, nasce no encontro do Eu com outro $\mathrm{Eu}(\mathrm{Tu})$. A diferença explicita que a reciprocidade se dá apenas na relação $\mathrm{Eu}$ - Tu e não na outra. Essa palavra que contempla reciprocidade, a qual ele denomina "mundo da relação" (BUBER, 2006, p. 55), divide-se em três esferas: a) a relação com a natureza, limitada pela linguagem; b) a com os homens, onde é "manifesta e explícita"; c) e com os seres espirituais, na qual, embora a relaçáo seja silenciosa, ainda gera linguagem.

Para o filósofo, a relação com o Tu se dá pela palavra-princípio, de modo que a experiência necessita de distanciamento, isto é, há casos, se ocorre distanciamento numa relação com o Tu, em que o Eu o experimenta como Isso. Nessa situaçáo, o Tu é experimentado como objeto. O Tu aparece para o Eu gratuitamente, mas cabe ao Eu dirigir-se a ele, entendido esse movimento como "ato de meu ser, meu ato essencial" (BUBER, 2006, p. 55). Daí o valor da relação, que é imediata e livre de obstáculos, pois somente assim o Eu a pode realizar. A relação demanda a presença e, diversamente, explica o filósofo, a experiência se dá com o já vivido, o que significa o privilégio da relação concreta, dialógica - que é também amorosa -, pois só assim o Eu realizará o próprio ser constituído nessa relaçáo. Para Buber (2006, p. 62), é no encontro com o Tu que se tece o ser do homem, como se comprova na citação seguinte: "[...] os entes vivem em torno de você, mas ao se aproximar de qualquer um deles você atinge sempre o ser”.

No trabalho inane, no maquinismo absorvente, no quotidiano esgotante e nas práticas da ciência, o Tu é reificado e transformado em Isso. Segundo Buber, essa é a singularidade da nossa vida: a partir do Eu, o Isso pode se tornar $\mathrm{Tu}$ ou o Tu tornar-se Isso; a relação mudar-se em experiência e experiência fazer-se relação. É possível se distanciar daquilo a que se está ligado e ligar-se àquilo que foi, um dia, distante. Buber esclarece esse assunto, asseverando que a primeira palavra-princípio, $\mathrm{Eu}-\mathrm{Tu}$, pode ser decomposta em duas partes (Eu e Tu), onde o Tu é anterior ao Eu; todavia, na decomposição da segunda, Eu - Isso, percebe-se que Isso é posterior ao $\mathrm{Eu}$, pois pede um distanciamento do entorno ${ }^{10}$. Eis como Buber o diz (2006, p. 67):

\footnotetext{
${ }^{10}$ A anterioridade do Tu aparece em Ortega y Gasset, no livro El hombre y la gente, localizada no nós, aquele espaço intersubjetivo no qual eu e tu estamos juntos. Somente posteriormente é que a noção de eu se estabelece. O curioso é que Eu e Tu alternam de lugar (1997, p. 147): "Temos, pois, que o homem, a parte do eu que sou, nos aparece como outro, e isso quer dizer - interessa que se tome com todo rigor - o outro quer dizer aquele com quem posso e tenho - ainda que náo queria - que alternar."
} 
[...] a proposição "eu vejo a árvore" é proferida de tal modo que ela não exprime mais uma relação entre o homem-Eu e a árvore-Tu, mas estabelece a percepção da árvore-objeto pelo homem-consciência. A frase erigiu a barreira entre sujeito e objeto; a palavra-princípio Eu-Isso, a palavra da separação, foi pronunciada.

Em outras palavras, o filósofo atribui à palavra-princípio $\mathrm{Eu}-\mathrm{Tu}$ um vínculo natural, característico de tempos remotos e, também, quando se refere à história do indivíduo, ao momento anterior ao nascimento. Conforme vimos, o Tu precede o Eu e a palavra-princípio $\mathrm{Eu}-\mathrm{Tu}$ supóe sua existência (a do Tu) a priori. A partir de então, o Eu vai se tornando consciente e, assim, fora da ligação natural com o Tu, o Eu consciente e distanciado necessita, para entrar em relação, reaproximar-se do Tu. Por isso, a busca da relação expressa o "instinto de tudo transformar em Tu" (BUBER, 2006, p. 69).

Por sua vez, a segunda palavra-princípio (Eu - Isso) contempla o distanciamento do entorno, quando o Eu se coloca diante de algo. Expressase, nas duas palavras-princípio, a consciência intencional de Edmund Husserl, no sentido de que não se fala mais de consciência, como no cartesianismo, mas numa inevitável cisão ou relação sujeito-objeto. Isso significa, como resume Carvalho (2014, p. 75), que Husserl, para descrever o modo como o mundo aparece na consciência, explicou que "[...] não lhe parece possível falar do mundo sem entender que ele está representado na consciência, nem há como se dedicar ao estudo da consciência sem considerar que ela está cheia de elementos do mundo". Partindo da noção de intencionalidade fenomenológica de Husserl, ${ }^{11}$ Martin Buber afirma que o Eu consciente e distanciado vê as qualidades do objeto, transforma-o em Isso:

O homem transformado em Eu que pronuncia o Eu-Isso [...] só pode atingir o núcleo poderoso, revelado a ele no $\mathrm{Tu}$, englobando todas as qualidades, [...] somente agora ele ordena as coisas em uma conexão espaçotemporal-causal; somente agora, ele determina a cada uma o seu lugar, a sua evolução, a sua mensurabilidade, a sua condição. [...] Eis uma verdade fundamental do mundo humano: somente o Isso pode ser ordenado. As coisas não são classificáveis senão na medida em que, deixando de ser nosso

\footnotetext{
${ }^{11} \mathrm{Na}$ quarta das suas meditaçóes, Husserl explicou o significado da intencionalidade da consciência, como se segue (1986, p. 89): "O Eu não se capta a si mesmo meramente como vida que flui, mas também como eu, como o eu que tem vivência do isto e do aquilo, o que ele vive este e aquele cogito como sendo do mesmo. Até agora temos estado ocupados com a consciência intencional da consciência e objeto, de cogito e cogitatum e por isso só havíamos destacado aquela síntese que polariza a multiplicidade de consciência real e possível nos objetos idênticos."
} 
$\mathrm{Tu}$, se transformam em nosso Isso. $\mathrm{O}$ Tu não conhece nenhum sistema de coordenadas (BUBER, 2006, p. 71).

Eis como Buber (2006, p. 74) resume a condiçáo do homem, a partir do que esclareceu sobre as palavras-princípio: “[...] o homem não pode viver sem o Isso, mas aquele que vive somente com o Isso náo é homem”. Dessa maneira, Husserl sintetiza o seu projeto fenomenológico: o homem vive no mundo e esse lhe aparece como objeto, contudo, para viver dessa forma, ele precisa estar aberto à transcendência que se manifesta no tempo. Dessa experiência da transcendência depende a relação temporal que é por ela iluminada.

Na Segunda Parte de Eu e Tu, Buber aborda a relação do Eu com o espírito e a contrapóe à relação Eu - Isso. Nesta última, o objeto está distanciado do Eu. Ela ocorre no passado - a relação sentimental, ao contrário, encontra-se na esfera do $\mathrm{Eu}$ - Tu e engloba o contato caloroso e presente. Nesse sentido, Buber escreve que a liberdade é atualidade plena e somente aí é que se pode falar em destino. Se não há liberdade, explica Buber, é a fatalidade, a causalidade que caracteriza a esfera do Isso. Ainda no tecer dessas oposiçóes exemplificativas, o pensador judeu contrapóe os conceitos de "pessoa" e de "egótico". Naturalmente, a primeira diz respeito à palavra-princípio Eu - Tu e a segunda, à Eu - Isso, na diferenciação adiante proposta:

A pessoa toma consciência de si como participante do ser, como um sercom, como um ente. $\mathrm{O}$ egótico toma consciência de si como um ente-queé-assim e nâo-de-outro-modo. A pessoa diz: "Eu sou”, o egótico diz: "Eu sou assim". "Conhece-te a ti mesmo" para a pessoas significa: conhece-te como ser. Para o egótico: conhece o teu modo de ser. Na medida em que o egótico se afasta dos outros, ele se distancia do Ser (BUBER, 2006, p. 93).

Estabelecida tal distinção, Buber dirá que, enquanto a pessoa se preocupa com o seu "si-mesmo", o egótico preocupa-se com o seu "meu": "minha espécie, minha raça” (BUBER, 2006, p. 93). Essa distinção somente é possível porque, como expresso na Primeira Parte da obra, o homem é duplo e dupla é sua relação com o mundo. Isso significa que ninguém é puramente pessoa ou egótico, mas transita entre uma e outra condição. Há épocas em que prevalece uma condição e épocas em que prevalece a outra. A preponderância de uma delas é vista na contraposição entre Eu e mundo, mundo e Eu, a qual emerge nos diferentes momentos da história. 
O mesmo pensamento encontramos na Terceira Parte, onde o autor contempla a relação com Deus como o Tu eterno, o Tu por essência ${ }^{12}$. De acordo com Buber, temos aí um paradoxo, pois o Grande Tu é o completamente Outro, mas também o integralmente presente. Nesse sentido, o Tu Eterno é o paradigma da relação, da palavra-princípio Eu - Tu. Encontrar Deus no mundo e o mundo em Deus é, segundo o autor, a santificação da própria vida. Para o autor, "aquele que verdadeiramente vai ao encontro do mundo vai ao encontro de Deus. É necessário se recolher e sair de si, realmente os dois, o 'um-e-outro' que é a unidade” (BUBER, 2006, p. 114).

\section{Diálogo E INTERSUBJETIVIDADE}

Em Eu e Tu, Martin Buber aborda a realidade dialógica das relaçóes humanas, incluindo-se as que se dão na esfera humana, com a natureza e as de caráter espiritual. $\mathrm{O}$ dialógico se realiza por meio das palavras-princípio $\mathrm{Eu}$ - Tu e Eu - Isso. Em Do diálogo e do dialógico, podemos observar o propósito do filósofo em aprofundar a relação Eu e Tu e de examinar como ela se efetiva na vida humana.

O filósofo entende que o diálogo pode se dar também no silêncio, isto é, que o signo, enquanto concretização da linguagem, não é necessário à comunicação, pois ela não necessita de gestos ou sons. Para Buber, o diálogo ocorre na medida em que algo se insere de maneira concreta no mundo dos homens e se faz comum na sequência temporal que o engloba. $\mathrm{O}$ que percebemos aqui é o desdobramento da palavra-princípio $\mathrm{Eu}$ - Tu, o qual, como foi frisado em $E u$ e Tu, liga o Eu que pronuncia ao outro mundo que não se confunde com ele. É o que o autor chama de "[...] transformação da comunicação em comunhão, portanto numa corporificação da palavra dialógica" (BUBER, 2007, p. 37).

Dessa maneira, o filósofo afirma que o diálogo autêntico pode se dar com qualquer atitude que relacione os homens, no que ele denomina “movimento básico" (BUBER, 2007, p. 56), isto é, no voltar-se um para o

\footnotetext{
${ }^{12}$ Von Zuben remete essa abordagem de Buber ao Tu eterno à influência de Kierkegaard e Schelling, embora esse dirigir-se diretamente a Deus como um Tu, sem intermediários, seja característica geral do luteranismo que impregnou a cultura germânica. Salienta Zuben (2003, p. 39): "As consideraçóes que Buber desenvolve sobre a relação dialogal em geral e a relação com o Tu eterno, em particular, acusam certas semelhanças, [...], com a perspectiva kierkegardiana da ideia de crença, ideia que nele se concretizou sob a influência de Schelling, quando este afirma que Deus não é um em si, que nada mais é do que pura relaçẫo".
} 
outro, que somente pode ser reconhecido na medida em que ocorre, na ação. Assim, mútua e reciprocamente receptivos, não apenas como observadores ou contempladores são os modos de relação da palavra-princípio Eu - Tu. Ela escapa do movimento monológico, que é o dobrar-se sobre si mesmo. Trata-se, portanto, de um encontro espontâneo, como salienta Luiz Veríssimo (2010, p. 112): "gostaríamos de pensar a proposição da condição originária da espontaneidade e da simplicidade no encontro entre a pessoa e o Tu". Aquele acontecimento comum é o que Buber (2007, p. 44) chama de "palavra que me é dirigida", e é nela que ele reconhece a possibilidade do distanciamento como algo superficial, não natural. Em outras palavras, é preciso reconhecer nesses acontecimentos o âmago da palavra dirigida, retirar dela o núcleo pulsante e significativo, para só entâo distanciar-se desse acontecimento e considerá-lo como Isso. Essa oposição, como vimos em Eu e Tu, é a melancolia da vida humana, é a dialética confusa entre borboleta e crisálida.

Considere-se, contudo, que "palavra dirigida", bem o sabemos, se encontra na categoria gramatical de voz passiva. Buber se pergunta: quem a dirige a nós? A resposta se apresenta ao filósofo no vocábulo "Deus". Mas, sendo assim o problema, é forçoso compreender que esse "Deus" é um Deus de momentos, de instantes, pois a palavra dirigida não é um acontecimento extasiante isolado, como experimentam os místicos, mas ocorre a todo momento, no tempo que nos tece. Isso não "diminui" o poder e a presença divina. Eis como o diz Buber (2007, p. 47, grifo do autor):

Eu nada mais possuo a náo ser o cotidiano do qual nunca sou afastado. [...] Não conheço mais outra plenitude a não ser a plenitude da exigência e da responsabilidade de cada hora mortal. [...] Não saberia dizer muito mais. Se isto for religião, então ela é simplesmente tudo, o tudo singelo, vivido, na sua possibilidade do diálogo. [...] Desta maneira, daqueles que dispensam os signos, dos que pronunciam as palavras na vida vivida, dos deuses do momento, constitui-se para nós, por identidade, o Senhor da voz, o Único".

Encontramos, entâo, o assunto da Terceira Parte de Eu e Tu desenvolvido e atualizado. Estamos diante da lei evangélica do amor ao próximo. Conforme Buber (2007, p. 48), esse pensamento tem perspectiva dialógica, quando afirma que "[...] a palavra daquele que quer falar com os homens, sem falar com Deus, não se realiza; mas a palavra daquele que quer falar com Deus, sem falar com os homens, extravia-se". 
Pode-se notar a oposição do diálogo verdadeiro e autêntico, em que se reconhece o Tu na relação com o Eu, e o monólogo, ainda que travestido em diálogo, no qual há apenas uma inautenticidade polifônica, onde cada interlocutor não tem outra intenção que se afirmar. Aqui não há relação, nem reciprocidade, muito menos amor. Não há Tu, mas só Eu. Dialógico e amor não são sinônimos, ressalta o filósofo: [...] a dialógica verdadeira e autêntica requer o amor, e o amor sem dialógica, "é o amor que permanece consigo mesmo, é este que se chama Lúcifer” (BUBER, 2007, p. 55). Para Buber, somente pelo diálogo o indivíduo pode se tornar pessoa.

\section{O enContro COM Sigmund Freud}

O encontro com Sigmund Freud ocorre no livro Moisés, obra de 1946, ocasião em que Martin Buber já residia em Israel. Há quem considere essa etapa da vida do filósofo como uma segunda navegação, distinta das preocupaçóes e problemas da fase alemã. ${ }^{13}$ No entanto, o livro Moisés, além do comentário do Exxodo, significa a afirmação do método histórico desenvolvido a partir das liçóes recolhidas entre as mais significativas contribuiçóes na fenomenologia histórica: Wartenberg, Dilthey e Gadamer. Buber explica que sua discordância de Freud na matéria estava bem fundamentada, pois ele se valia desses reconhecidos hermeneutas, como se esclarece no texto seguinte (CARVALHO, 2017, p. 65):

Aspecto fundamental dessa metodologia histórica é que ela adota a orientaçấo presente numa carta de Paul York Wartenberg a seu professor Wilhelm Dilthey. Paul Wartenberg dizia que não havia vantagem em utilizar categorias da teologia contemporânea, como: panteísmo, monoteísmo, teísmo, panenteísmo, por exemplo, no exame dos textos bíblicos, porque tais categorias não ajudavam na sua compreensão. E assim é porque, quando se comparam os deuses daqueles povos, estão distantes os que parecem próximos e vice-versa.

O método desenvolvido por Buber, a partir desses mestres, significava um encaminhamento da fenomenologia para a razão histórica, acompanhando a última etapa de Edmund Husserl, diferentemente do que o filósofo propusera

\footnotetext{
${ }^{13}$ Urbano Zillles (1979, p. 7) assinala, na apresentação da obra de Antônio Sidekum, A intersubjetividade em Martin Buber, que as duas navegaçóes contemplam temática e assunto diferentes. Ele escreveu sobre Eu e Tu: "esta obra situa-se no período alemão (até 1938), que se distingue do período israelense (depois de 1938)."
} 
na fase inicial de sua meditação ${ }^{14}$. Sobre essa evolução do pensamento de Edmund Husserl (2014, p. 75), lê-se: "A leitura dos principais livros de Husserl sugere que ele passou por etapas evolutivas, sendo perfeitamente distintas o logicismo da fase inicial, uma espécie de vitalismo histórico na etapa final, havendo um período idealista intermediário". O propósito de Husserl é o de penetrar nos estudos históricos, com base nas ciências do espírito. Isso parece claro, quando se consideram os escritos de Husserl publicados desde 1933, na Revista Kantstudien, e apropriados por Merleau-Ponty. ${ }^{15}$ Isso significa um esforço de compreensão dos fatos diferente do que se tem dos fatos naturais, como explica Heimsoeth. ${ }^{16}$

O diálogo de Martin Buber com Sigmund Freud pede que se entenda o essencial do livro $O$ homem Moisés e a religiáo monoteísta (2017). $\mathrm{Na}$ primeira nota do capítulo 4 do livro Martin Buber, a filosofia e outros escritos sobre o diálogo e a intersubjetividade (2017), comenta-se esse livro de Freud, que também se encontra no volume XXIII da tradução das Obras Completas de Freud, feita pela Editora Imago (1974). A tradução aqui utilizada, feita diretamente do alemão por Renato Zwick, com revisão técnica e prefaciada por Betty Bernardo Fuks, saiu recentemente (Porto Alegre, L\&PM, 2014, 192 p.) com título diferente de Moisés e o monoteísmo da Imago. A tradução de Zwick permite uma melhor e mais profunda compreensão do projeto freudiano. Eis a síntese feita por Carvalho (2017, p.63/4):

O livro [O homem Moisés e a religiäo monoteista] explica a teoria da neurose desenvolvida pelo pai da psicanálise estabelecendo um vínculo entre ela e a religiâo. Foi um texto escrito na maturidade intelectual e Freud se esforçou

\footnotetext{
${ }^{14} \mathrm{Na}$ comunicação Ortega como fenomenólogo, Javier San Martin Sala (2007, p. 39) explica que as críticas de Ortega y Gasset sobre a despreocupaçāo da fenomenologia com a história se deve ao fato de ele não conhecer as obras do segundo Husserl, quando, diversamente do que ocorreu nos trabalhos iniciais, como as Investigaçôes Lógicas, ele demonstra interesse pela experiência histórica: "Porque se a fenomenologia levava em seu seio, como sabemos depois dos textos sobre a renovaçâo da Europa, o que disse Ortega, é radicalmente errôneo e resultado dele se fixar em uma visáo profundamente parcial do que Husserl estava fazendo. Na realidade a obra de Husserl está em função da história e a história é uma das maiores preocupaçôes de Husserl em data bastante cedo como 1905, quando começa a controlar o conceito de individualização, que é característico da história”.

${ }^{15}$ Confira a análise dessa nova visão da filosofia de Husserl, no artigo "Ortega como Fenomenólogo", de Javier Sala, publicado no livro Ortega y Gasset, leituras críticas no cinquentenário da morte do autor, p. 30 a 34 .

${ }^{16}$ Em A filosofia do século XX. Heins Heimzoetth (1938, p. 40-41) comenta a questáo, como se segue: "As chamadas ciências do espírito (tanto as de índole histórico, com as sistemáticas) reclamam, com efeito, em harmonia com essa orientaçấo, um conceito próprio e específico de experiência, categorias também só suas, uma sistematização sua, e uma forma particular de consciência em que o sujeito cognoscente se conhece a si mesmo".
} 
por concluí-lo. A publicação ocorreu no ano do seu falecimento (1939). O livro contém três ensaios sendo dois deles um esforço para entender a figura de Moisés, o principal profeta do judaísmo, a formação do povo judeu e o surgimento do cristianismo. Segundo estudiosos de Freud, o livro cumpriu o desafio existencial de explicar as razóes do ódio ao judeu desencadeado pelo nazismo. A obra atribuiu ao monoteísmo o papel de substituir o matriarcado pelo patriarcado, expresso no reconhecimento de um Deus único e poderoso (o episódio do Sinai). Esse Deus assume a imagem do pai primordial, que será simultaneamente amado e temido. A morte desse pai e sua substituição por Deus permitiu o estabelecimento da vida comunitária pelo recalcamento das pulsóes primitivas. $\mathrm{O}$ terceiro ensaio desenvolve mais amplamente a teoria da neurose e a associa à morte do pai primordial e sua substituição por um totem. Esse processo social foi internalizado, o que permitiu a diferenciação da estrutura psíquica em id, ego e superego. À parte das interpretaçôes históricas, ele considera a construção do texto bíblico o retorno do reprimido. Essa última estrutura assegura a proibição e as censuras antes exercidas pelo pai pela identificação com ele e cria a expectativa da recompensa pelo cumprimento das normas que ele propôs. Esse material pode voltar em forma de sintoma. Segundo Freud (2014, p. 178): "O retorno do recalcado se realiza lentamente, com certeza não de maneira espontânea, e sim sob a influência de todas as modificaçóes nas condiçóes humanas de vida que preenchem a história cultural dos seres humanos".

Sigmund Freud adota a teoria da neurose, que ele estruturara anteriormente em Totem e Tabu, no estudo histórico que dedicou ao homem Moisés e explica que o pai primordial morto pelos membros do clá, o qual passara a ser representado no animal totêmico de Totem e Tabu, é o Deus que se estruturou no judaísmo. Essa é a tese de Freud, no seu livro sobre Moisés. Podemos acompanhar, na continuidade do relato de Carvalho, o modo como se estruturou a noção de monoteísmo, nas diversas sociedades humanas. A experiência judaica do Deus único é o ponto de chegada desse processo genericamente descrito por Freud, em Totem e Tabu.

No início, explica, o totem é um deus antropomorfo, com cabeça de animal. (Ibidem): "Mais tarde se transforma preferentemente nesse animal específico, depois esse animal se torna sagrado para ele e se converte em seu acompanhante predileto, ou ele matou o animal e leva um cognome que corresponda a isso. Entre o animal totêmico e Deus surge o herói, muitas vezes como estágio preliminar da divinizaçáo. A ideia de uma divindade suprema parece surgir cedo, de início apenas de maneira vaga, sem interferir nos interesses cotidianos dos seres humanos. Com a união das tribos e dos povos antigos em unidades maiores, os deuses também se 
organizam em famílias, em hierarquias. Muitas vezes um deles é elevado à categoria de soberano acima de deuses e homens. De maneira hesitante, ocorre entâo o passo seguinte, de adorar um só Deus, e por fim sucede a decisáo de conceder todo o poder a um único deus e não tolerar quaisquer outros deuses ao seu lado. Apenas com isso fora restaurada a magnificência do pai da horda primordial, e os afetos que lhe diziam respeito puderam ser repetidos" (CARVALHO, 2017, p. 64).

Para a interpretação da figura histórica de Moisés, Freud se baseou em historiadores conhecidos na época, como J. H. Breasted e Eduard Meyer, e na conhecida estratégia usada pelos teólogos bíblicos, que dividiam o texto sagrado nas tradiçóes Javista, Eloísta e Deuteronomista. Com base nessas referências, Freud concluiu que a história narrada na Bíblia é uma lenda recheada de erros históricos. Ele assevera que Moisés era um governador de uma província egípcia, um adepto do deus Aton e que, depois que os sacerdotes reconstituíram a antiga crença nos deuses tradicionais, adotou o povo judeu como próprio. Então, ele impôs ferozmente sua fé a esse povo, gerando uma revolta que levou a sua morte. Foi um outro Moisés quem conduziu o povo depois do episódio do Sinai.

Afirma, portanto, que existiram duas figuras históricas de nome Moisés, e que o judaísmo é uma mistura entre o culto de Aton combinado com o Deus das tribos nômades com as quais se juntaram os grupos que saíram do Egito. Javé é, portanto, nessa interpretaçáo freudiana, síntese de dois deuses antigos. Sobre essa interpretação, comenta Freud (2014, p. 42):

Talvez se objete que as circunstâncias de formação e da transformação das lendas são obscuras demais para justificar uma conclusão como a nossa, e que as tradiçóes sobre a figura heroica de Moisés, em sua confusão, suas contradiçôes e com os sinais inequívocos de remodelaçôes e de sobreposições tendenciosas repetidas ao longo de séculos, precisam frustrar todos os esforços para trazer à luz o núcleo da verdade histórica que há por trás delas.

Martin Buber, diversamente, assumiu como correta a narrativa histórica encontrada no livro do Exodo. Ele nega qualidade ao trabalho dos historiadores em quem Freud se baseou e à interpretação teológica das tradiçóes históricas do texto bíblico. Não é necessário aprofundar as críticas a Freud. Todavia, para o propósito desta comunicação, é importante observar que o método que ele empregou para defender sua tese foi uma síntese do que a fenomenologia 
produzira de mais significativo, como hermenêutica literária e histórica. Logo, reunia o principal hermeneuta conhecido e os nomes mais destacados da historiografia alemã: Paul York Wartenberg, Wilhelm Dilthey e Hans Georg Gadamer. Foi com base no ensinamento desses autores que Buber construiu o seu método de investigação do livro do Exodo.

No entanto, o seu método precisava náo apenas valer-se dos maiores nomes que havia na Alemanha, no momento, mas enfrentar as fragilidades que os fenomenólogos da nova geração começaram a apontar, no trabalho dos mestres. Trata-se de descobrir a vida mesmo no texto, como propôs Ortega y Gasset. Frisa Buber (1949, p. 12): "Estudando o texto durante muitos anos, convenci-me de que em muitos casos a forma completa o fundo, quer dizer, que muitas coisas importantes são reveladas por seus meios”.

Esse assunto foi comentado por Carvalho, em Martin Buber, a filosofia $e$ outros escritos sobre o diálogo e a intersubjetividade, no qual se focaliza a necessidade de entender a vida mesma contida nos textos e onde se deixa clara a posição de Buber (2017, p. 87), diante do que pensava Ortega a respeito desse conceito:

E, ao fazer um estudo de um documento histórico, avalia Buber, era necessário ir além de Dilthey. Era preciso ir além do texto escrito para nele descobrir as tradiçóes documentadas que expressam a vida espontânea, aquela vida mesmo que é, verdadeiramente, o que mais importa quando se pretende entender uma época ou como as pessoas daquele tempo pensavam suas questôes. Dilthey não aprofundara a historicidade da espontaneidade vital e seu método carecia disso. Foi o que observaram e procuraram corrigir Gadamer e Ortega y Gasset, esses últimos proponentes de uma nova forma de pensar a vida na história. Dilthey tratou a vida indo além de Stuart Mill, mas sem se afastar da metodologia utilizada pelas ciências da natureza. Quanto à influência idealista, presente na valorização da história, é preciso recordar que ela não considerava o caráter histórico da experiência. Em Schleiermacher, por exemplo, a hermenêutica estava centrada na relaçáo eu-tu, ou melhor, na compreensão do primeiro pelo segundo.

Assumindo os ensinamentos dos nomes mais reconhecidos da hermenêutica histórica, Martin Buber desenvolve o seu método de investigação da história. Ele aborda a relação intersubjetiva como a própria realidade fundamental a ser colhida, conforme propusera no livro Eu e Tu. Eis como Carvalho comenta o método desenvolvido no espírito daquela obra paradigmática: 
Dilthey havia concebido o mundo histórico como um texto a decifrar. Um texto onde tudo pode ser compreendido, pois ele se forma como partes de um todo onde vida e história possuem um sentido ou uma razáo. Sobre esse aspecto já observara Gadamer, a experiência histórica define-se pela acumulaçáo histórica o que impede o uso de um método puro como queria Dilthey. Este problema ocorre, concluiu Gadamer, porque a atenção com a vida formulada por Dilthey (id., p. 44): "nunca se harmonizou com a concepção cartesiana de ciência”. Portanto, o trabalho de Buber também precisou entrar em questóes sofisticadas de metodologia histórica, mesmo partindo de Dilthey, precisou considerar as críticas que Gadamer lhe fizera. Esse problema ele resolveu com o estudo das sucessivas camadas que compóem o livro do Êxodo. Também é preciso considerar que a investigação histórica que partira da metodologia utilizada por Dilthey com elementos da hermenêutica de Gadamer, incorporou a preocupação com as crenças que orientam o homem na existência. (BUBER, 2017, p. 87)

Em síntese, Martin Buber assumiu os aspectos fundamentais da fenomenologia histórica e a desenvolveu na mesma linha que os fenomenólogos, incluído Ortega nesse grupo, estavam propondo.

\section{Buber E A PSICANÁlISE ANALÍTICA DE JUNG}

Martin Buber procurou entender o que se passava na primeira metade do século XX. Suas observaçóes sobre aqueles dias foram apresentadas no livro Eclipse de Deus (1952). Ele o escreveu num tempo de dificuldades econômicas que se seguiu à crise de 29 e especialmente durante a Segunda Grande Guerra. Aquele foi um momento de revisão da mentalidade positivista, segundo a qual o mundo podia ser compreendido pela ciência, inclusive as questôes morais, políticas e sociais seriam consideradas com o mesmo método das ciências. Também era necessário entender a brutalidade e atrocidades cometidas naqueles dias. De modo geral, para os homens daquele mundo, Deus já não tinha nada a dizer. Por isso, junto com o dogmatismo religioso que justificara o direito divino dos reis e o absolutismo combatido pelo iluminismo moderno, se perdera, por força das filosofias dos séculos XIX e XX, o sentido e significado da fé religiosa das antigas geraçóes.

É nesse contexto que alguns pensadores procuram recuperar, em outros termos, o sentido da fé em Deus. Foi o que fez Gabriel Marcel, o qual, no contexto cristão, pensou um Deus vivo e próximo do crente, deixando de lado 
as tentativas de reduzi-lo a causa física ou inteligível do mundo ${ }^{17}$. No mesmo espírito trabalhou Teilhard de Chardin, que encontrou na ideia de evolução do mundo um sentido e direção para Deus. É, como partícipe desse movimento, que Martin Buber abordará o encontro do homem com Deus, ao mesmo tempo que critica os exageros do positivismo como filosofia da ciência. Buber, como Gabriel Marcel, falará de um Deus vivo com quem se dialoga. Em dois capítulos de Eclipse de Deus, já publicados anteriormente, é que o assunto foi aprofundado: "Religiáo e Filosofia" (antes editado em Europäischen Revue, 1929, p. 325-335) e "O amor a Deus e a ideia de Deus" (publicado em Neuen Schweizer Runddschau, 1947, p. 497-506).

Esses capítulos nasceram como revisão dos artigos publicados. O que se quer contudo destacar, no âmbito dessa comunicação, é o que está no quarto capítulo de Eclipse de Deus, onde há uma crítica ao psicanalista Carl Gustav Jung. A tradução brasileira de Eclipse de Deus adiciona o ensaio no qual Jung responde às críticas de Buber, e também contempla a réplica do filósofo judeu a esse ensaio de Jung. O livro permite, portanto, acompanhar o debate e, além das posiçóes filosóficas de Buber, examinar sua crítica à psicanálise de Jung. A resposta que este deu às ponderaçóes de Buber foi intitulada Resposta a Martin Buber e foi publicada inicialmente na revista Merkur (Stuttgart, ano VI, fascículo 8, 1952). Na ediçáo brasileira das Obras Completas de Jung, esse texto aparece como "Religião e Psicologia" e foi publicado no volume Psicologia e religiáo oriental (Petrópolis: Vozes, 2005. v. XI, 615-622).

Vejamos, a seguir, o teor da crítica de Buber. Ele utiliza um argumento já empregado por outros fenomenólogos, isto é, o fato de a ciência pretender ir além do que os dados permitiam e ocupar, assim, outros espaços da cultura, inclusive o da religião e da fé. Eis como Buber (2007 b, p. 76) o afirma: "ele [Jung] transpóe com soberana liberdade as fronteiras da psicologia em seus pontos mais essenciais, mas quase sem que perceba ou mesmo justifique porque o faz".

Portanto, a crítica situa Jung na mentalidade positivista que recusava a presença de Deus no mundo e assumia, sem crítica, o discurso apresentado como científico. Buber menciona a transposição categorial que é estudar outros campos da realidade com as mesmas categorias empregadas e válidas

\footnotetext{
${ }^{17}$ Bartholo Jr. resumiu outros problemas que seriam enfrentados pelo filósofo, como se verifica na sequência (2001, p. 9): "Outros como Franz Rosenzweig e Gabriel Marcel, apontam quase simultaneamente para a mesma urgência, de que seu /nosso tempo está grávido: curar as profundas feridas abertas na face humana pela falsa opção entre o individualismo possessivo e o coletivismo impositivo".
} 
num campo diverso. No livro Martin Buber, a filosofia e outros escritos sobre o diálogo e a intersubjetividade, Carvalho (2017, p. 37) resume o fundamental dessa crítica:

Jung vai além de onde autorizam suas experiências clínicas quando reduz a religiáo à manifestação de elementos inconscientes, que brotam da alma humana. Deus náo é um Ente ou essência a que corresponda um componente psíquico, mas é exatamente esse conteúdo, um produto da alma humana considerada uma realidade metafísica essencial. A partir de uma análise fenomenológica da consciência, Buber recusa a noção de alma como realidade absoluta, pois a consciência se forma na relaçáo com o mundo. Da forma como entende Deus, Jung náo alcança a experiência religiosa: fica na experiência de si próprio. A representaçáo dessa experiência sáo as mandalas (id., p. 83): "símbolos em forma de círculos, que Jung encontrou não apenas em diversas culturas religiosas, sobretudo no Oriente e na Alta Idade Média, mas também em desenhos de neuróticos e psicopatas". As mandalas são representaçōes da totalidade, fechadas em si mesmo, e que contém elementos complementares como o feminino e o masculino, o claro e o escuro, embora Jung não tenha dito que essas imagens substituíssem a divindade.

No que concerne ao processo dinâmico do desenvolvimento da personalidade, com o qual Jung descreve o movimento da psique humana, o psicanalista o descreve como união de elementos conscientes e inconscientes que produzem nova figuração do $S_{e l f}{ }^{18}$. O Self, núcleo mais profundo da personalidade, inclui o Eu e outro, ou outros, isto é, o mundo, por conseguinte, a relação dialógica estudada por Buber em Eu e Tu. A continuidade da análise de Buber foi assim sintetizada por Carvalho (2017, p. 37):

Nesse ponto, Buber observa que o outro continua sendo o outro que (id., p. 87): "vem ao meu encontro de tal forma que minha vida entra em contato com a dele como com algo que não é e não pode vir a ser, minha alma não a inclui e nem a pode incluir". Como ponto de chegada, o processo de individuação, no Self, é a união de opostos que se completam, do bem e do mal, de Cristo e do Anticristo, etc. É um processo interno de organizaçáo psíquica. Daí conclui Buber (id., p. 88): "o Selfé uma totalidade pura e, como tal, indistinguível da imagem de Deus". O Selfé um modelo que

\footnotetext{
${ }^{18}$ No capítulo "O Processo de Individuação" (p. 158- 229), onde M. L. von Franz parte do livro O homem e seus símbolos, concebido e organizado por Carl Gustav Jung, encontra-se a explicação do que era o Self. Assinala Franz (1977, p. 196): "Se um indivíduo lutou séria e longamente com a sua anima ou seu animus de maneira a não se deixar identificar parcialmente com eles, o inconsciente muda seu caráter dominante e aparece uma nova forma simbólica, representada pelo Self, o núcleo mais profundo da psique".
} 
representa os sistemas monoteístas. Porém, além de excluir o mundo e o que está fora da alma, o Self representa a ideia gnóstica de Deus, que Buber encontra nos escritos de juventude de Jung. Explica Buber (id., p. 90): "Essa figura, que une em si a Cristo e Satâ, é, como realização da identidade de Deus como homem, a última figura descida à terra daquele Deus gnóstico que Jung antes havia professado e a quem permaneceu fiel". A sequência desse debate encontra-se em artigos que foram incluídos nessa edição brasileira.

Jung explicou, na resposta às críticas de Buber, que seus escritos eram de um psiquiatra, o qual interpretava cientificamente os movimentos da vida psicológica, e não trabalho de um filósofo ou teólogo. Comenta, em seguida, que ele já foi considerado coisas muito distintas e contrárias, como gnóstico e agnóstico, místico e materialista, embora não entendesse como adequada nenhuma dessas referências que lhe foram imputadas e que Buber também utilizara. Do produto da consciência Jung (2007 b, p. 123) enfatiza:

Nisso tenho plena consciência de estar lidando com concepçóes antropomórficas e não com deuses e anjos reais, embora tais imagens arquetípicas, graças a sua energia específica, se comportem de forma tão independente que metafisicamente não poderia designá-la de outra maneira que não como demônios psíquicos.

O principal da resposta que o psicanalista deu a Buber também foi resumida por Carvalho (2017, p. 44):

Jung afirma que Buber entendeu mal o que ele denominava realidade da alma, que não era mais que simples descrição de fatos psíquicos e parte do processo dialético da individuação. Esses fenômenos são expressóes do inconsciente e não propriamente pensamentos, esclarece. Na psique humana, esses conteúdos religiosos aparecem como um $\mathrm{Tu}$, porque contrapóem-se ao Eu subjetivo. E as mais inexplicáveis manifestaçóes da violência contemporânea: a morte de milhóes de judeus pelos nazistas, a bomba atômica e o tráfico de escravos na Rússia parecem, a Jung, materializaçáo dos demônios íntimos que atormentam as pessoas. Nesse sentido, toda a representação de Deus, de igual modo, é expressão de algo íntimo do homem, portanto, um fenômeno psíquico. Esclarecido isso, Jung não considera que suas afirmaçóes possam ser interpretadas como possuindo caráter metafísico ou teológico, mas unicamente empírico. E recusa a crítica de Buber como se verifica no texto que se segue (id., p. 128): Quando sou da opiniáo que todas as afirmaçóes sobre Deus partem em primeira linha da alma, e por isso, é preciso distingui-las do ser 
metafísico, com isso nem Deus foi negado, nem o homem foi colocado no lugar de Deus.

O que Jung destacou é que seus escritos não foram bem entendidos por Buber, que se comportava como teólogo ou filósofo interpretando uma teoria científica. Diante dessas palavras de Jung, Buber preparou uma réplica, explicando a diferença entre seu pensamento e a noção de religião dos psicanalistas e diferenciando o Deus da Filosofia (ao qual parece se referir Jung) do Deus Bíblico. Buber esclareceu que não contestava as observaçóes clínicas do psiquiatra, nem o material colhido da prática médica, mas recusava a transposição das conclusôes do campo científico para o religioso. Em outras palavras, ele entendia que Jung formulava afirmaçôes sobre assuntos religiosos que ultrapassavam a esfera da Psiquiatria e da Psicologia.

Essa crítica de Buber também foi assim retomada por Carvalho (2017, p. 45):

E se nos detivermos às justificativas de ambos, parece correta a observação de Buber, porque mesmo que se reconheça a validade dos arquétipos, como Jung os entendeu, não parece legítimo concluir daí que (id., p. 132): "não exista um Deus desvinculado do sujeito humano". Aliás, é essa tese que ele recusa na interpretação que Freud dá à fé judaica. Buber entende que Deus se manifesta em formas que o homem possa estudá-lo, mas isso não o esgota, nem o restringe a esse objeto. É o mesmo argumento de Jaspers no que se refere à totalidade da vida humana, a existência do homem pode ser estudada em aspectos parciais pela ciência, mas náo se deixa ver na totalidade. Nesse ponto, a dificuldade epistemológica é a mesma de quando se estuda Deus. No capítulo dedicado $\grave{A}$ variedade genérica do Homem, na Psicopatologia Geral, Jaspers explica (1979, v. II, p. 748): "É errado pensar que a análise de fatores elementares esgote o respectivo objeto, e é errado pensar que o todo da ideia seja, ele próprio, fator que se possa reconhecer e dominar como tal”.

\section{CONSIDERAÇÓES FINAIS}

Martin Buber representa, no âmbito da filosofia existencial, o grande expoente dos estudos sobre as relaçóes humanas. Sua contribuição mais significativa para essa questão está em $E u$ e Tu e no livro Do diálogo e do dialógico, livros onde ele explica que a autêntica existência humana se constrói como relação. O aprofundamento que realizou nos conceitos "relação" e "diálogo", nas duas obras mencionadas, ampliou os conhecimentos da 
analítica da existência ${ }^{19}$. Embora esse fosse tema de outros fenomenólogos, as contribuiçôes aqui resumidas são fundamentais para os que se dedicam às ciências humanas, especialmente Psicologia, Educação e Sociologia.

Nesta comunicação, indica-se que a fenomenologia da relação de Buber vai além do solipsismo moderno, cartesiano, porque recusa uma consciência isolada e organizadora do mundo. Mostramos, neste artigo, que Buber adota a consciência intencional de Husserl, considerando-a a base de suas palavrasprincípio ou, ainda melhor, aquela ideia orteguiana de referir-se ao Eu na relação com a circunstância, a qual, para nosso pensador, se revela nas relaçôes com o Tu e com o Isso. Dito à moda de Husserl, não há um Eu sem um Tu ou um Isso e não existem essas realidades sem o Eu. A consciência intencional buberiana mantém diálogos intencionais e está na base das críticas que fez aos psicanalistas. Essas críticas vão no sentido de recusar à psicanálise o status de ciência total e de abrir espaço para a chamada psicologia fenomenológica ${ }^{20} \mathrm{e}$ para estudos históricos.

Quando se tem em vista o espaço ocupado por Buber, na escola existencial, naquele sentido indicado por Heinemann no capítulo sobre antropologia filosófica, em $A$ filosofia no século $X X$, nele enxergarmos o protagonismo da fenomenologia da relaçáo, aquele pensador que destaca o espaço que há entre o sujeito e o objeto da consciência, aquele que tematiza o intervalo, que se abre entre o Eu e cada um dos modos de objetos (Tu ou Isso) com os quais se dá na relação ou na experiência. Portanto, as palavras-princípio resumem duas formas de o homem se relacionar no mundo e expressam o discurso filosófico e científico.

Parece necessário ainda lembrar que, num mundo em que os mestres da suspeita (Freud, Marx e Nietzsche) anunciaram a morte de Deus e sepultaram o humanismo, Buber é um dos autores cujas teses articulam o que há de mais

\footnotetext{
${ }^{19}$ Buber é um pensador muito original e marca posição própria, entre os filósofos da existência. De um lado, é preciso não desconhecer que a escola existencialista não possui pontos rígidos, principalmente tomada de posição sobre importantes questốes existenciais. E, nesse sentido, ele se insere perfeitamente na escola, como se aufere deste texto de von Zuben (2003, p. 183): "Este estudo procura mostrar a preocupação de Martin Buber quanto ao grande enigma que vem desafiando a curiosidade questionadora do homem no transcurso de sua história, a questão da sua existência”.

${ }^{20}$ Von Zuben observa que a fenomenologia do diálogo de Buber inspirou a clínica fenomenológica (2003, p. 165): "muitos especialistas de renome estudaram a obra de Buber e elaboraram articulaçóes nas mais diversas perspectivas, o mais das vezes escolhendo a categoria da relaçâo ou do diálogo para as análises e propostas sobre as principais questóes no campo da psicologia e da psicoterapia. Mais recentemente, muitos especialistas vinculados à terapia da Gestalt têm contribuído significativamente para as pesquisas e estudos correlacionando essa teoria com o pensamento dialógico de Buber".
} 
humano no homem, não só retomando o humanismo ${ }^{21}$, mas preocupado em trazer de volta o divino no mundo, em um humanismo ontológico.

CARVALHO, J. M.; TOMAZ, M. S. C Martin Buber and the phenomenology: the encounter in philosophical and psychological discourse. Trans/form/ação, Marília, v. 43, n. 4, p. 203-224, Out./Dez., 2020.

\begin{abstract}
The fundamental contribution of Buber to the existential phenomenology is to attribute to the principle words I-Thou and I-It, by means of the intentionality of consciousness, a decisive role in the dialogue and in the encounter. This occurs by the presentification and detachment of the ones involved in the debate. These words were fundamental to explain the intersubjectivites relations and with the world, relations which are essential to clarify the discourse that comes from philosophy and science. We try to present a deeply concern about the distinction between the Buber's principle words and its repercussion in the relation therapist - patient in the psychological and medical clinics. Moreover, we will touch the dialog that Buber sustained with Freud and Jung. With the first, it is noticeable the inception of the meaning of historicity in the construction of life to refuse a notion of culture as an Oedipus projection. Buber refuse too, with the second, to reduce the dialogue with the sacred to a psychic function.
\end{abstract}

Keywords: Phenomenology. Intentionality. Philosophy. Health. Psychology.

\title{
REFERÊNCIAS
}

BARTHOLO JR., Roberto. Você e Eu - Martin Buber; presença palavra. Rio de Janeiro, Garamond, 2001.

BUBER, Martin. Moisés. Buenos Aires, Imán, 1949.

BUBER, Martin. Eu e Tu. 10 ed. Trad. Newton Aquiles von Zuben. São Paulo: Centauro, 2006. 152 p.

BUBER, Martin. Do diálogo e do dialógico. Trad. Marta Ekstein de Souza Queiroz e Regina Weinberg. São Paulo: Perspectiva, 2007. 171 p.

BUBER, Martin. Eclipse de Deus. Campinas, Verus, 2007 b.

${ }^{21}$ Certos autores, como Eduardo Oyakawa, enxergam na reação buberiana ao ateísmo moderno e ao individualismo político um traço do romantismo alemão. A reação ao ateísmo se explica melhor pelo diálogo com a vertente religiosa da fenomenologia existencial; seu pensamento social e político parece, contudo, próximo dos românticos, pela construção da ideia de nação e articulação de um princípio fundador do povo. Eis o que Oyakawa afirma (p. 35): "hauriu do romantismo a contestação dos que pressentiam na modernidade os traços inexcedíveis de impessoalidade e alienaçôes sociais crescentes. Propugnou uma nova forma de convivência humana baseada nos princípios da comunidade”. 
CARVALHO, José Mauricio de. História da filosofia contemporânea. São João del-Rei, Nead, 2014. 169 p.

CARVALHO, José Mauricio de Martin Buber, a filosofia e outros escritos sobre o diálogo e a intersubjetividade. São Paulo, filoczar, 2017. 259 p.

CROMBERG, Mônica Udler. A crisálida da filosofia. São Paulo, Associação Editorial Humanitas, 2002, 222 p.

FREUD, Simund. O homem Moisés e a religiaao monoteísta. Porto Alegre, Le PM, 2014. 192 p.

HEIMSOETH, Heins. A filosofia no século XX. São Paulo, Saraiva, 1938. 168 p.

HEINEMANN, Fritz. A filosofia no século XX. Trad. e prefácio de Alexandre Morujão. 2 ed.; Lisboa, Calouste Gulbenkian, 2006. 574 p.

HUSSERL, Edmund. Meditaciones cartesianas. Madrid, Gama, 1986. 222 p.

JUNG, Carl Gustav (org.). O homem e seus símbolos. Rio de Janeiro, Nova Fronteira, $1977.316 \mathrm{p}$.

LUIJPEN, Wilhemus Antonius Maria. Introdução à fenomenología existencial. São Paulo: EPU, 1973. 400 p.

ORTEGA Y GASSET, José. El hombre y la gente. Obras Completas. 2a reimpresión. v. VII, Madrid, Alianza, 1997.71-269 p.

OYAKAVA, Eduardo. A espiritualidade da palavra: Martin Buber e Friedrich Hölderlin. São Paulo, Stilgraf, 2010. 176 p.

SALA, Javier San Martín. Ortega como fenomenólogo. IN: AMOEDO, M., BARROS DIAS, J.M. e DELGADO, A.S. José Ortega y Gasset leituras críticas no cinquentenário da morte do autor. Évora, Universidade de Évora, 2007. 21-41 p.

SIDEKUM, Antônio. A intersubjetividade em Martin Buber. Porto Alegre, Escola Superior de Teologia São Lourenço de Brindes. Caxias do Sul, Universidade de Caxias do Sul, 1979. 112 p.

VERÍSSIMO, Luiz José. A ética da reciprocidade, diálogo com Martin Buber. Rio de Janeiro, UAPÊ, 2010. 201 p.

Von ZUBEN, Newton Aquiles. Martin Buber, cumplicidade e diálogo. Bauru, EDUSC, 2003. 232 p.

Recebido: 28/5/2018

Aceito: 24/02/2020 